\title{
CRIS - service for input, storage and analysis of the biodiversity data of the cryptogams
}

\author{
Alexey V. Melekhin ${ }^{1}$, Denis A. Davydov ${ }^{1,2}$, Eugene A. Borovichev², Sergei S. Shalygin ${ }^{3}$, \\ Nadezhda A. Konstantinova ${ }^{*}$ \\ ${ }^{1}$ Polar-Alpine Botanical Garden-Institute of the Kola Science Center of RAS, Apatity, 184256, Russia. \\ E-mail: melihen@yandex.ru, d_disa@mail.ru, nadya50@list.ru \\ ${ }^{2}$ Institute of the Industrial Ecology Problems of the North of the Kola Science Center of RAS, Apatity, 184209, Russia. \\ E-mail: borovichyok@mail.ru \\ ${ }^{3}$ Texas A\&M University Corpus Christi. E-mail: sergei.shalygin@tamucc.edu \\ *Author for correspondence
}

\begin{abstract}
Here we describe Cryptogamic Russian Information System (CRIS), a web service cataloguing the biodiversity of cryptogams: cyanobacteria, fungi (including lichens), and bryophytes. CRIS incorporates a wide spectrum of data types, allowing for greater ease of use. It is possible to print the labels for herbarium collections, to input literature references, media files, etc., using CRIS which has a flexible interface and specific technical abilities. Currently, CRIS contains - 90,000 herbarium records, including 67,861 records of bryophytes, 12,486 records of lichens and 3,800 records of cyanobacteria. Data analysis of the different taxonomic groups is provided below. Perspectives and directions for the future development of CRIS are discussed.
\end{abstract}

Keywords: biodiversity, herbarium collections, information system, cyanobacteria, lichens, bryophytes

\section{INTRODUCTION}

Herbaria and living biological collections are the major sources of information on biodiversity (Veiga et al., 2017). In the early 2000s, different biological Information Systems (IS) were developed with the aim of organizing complex data (Bisby, 2000; Ivanova \& Shashkov, 2017). Despite the development of these systems, there are still many unresolved questions related to the maintenance and distribution of such IS (Altman, 2004; Bourne, 2005; Shanmughavel, 2007; Vissers et al., 2017). It is likely that many researchers and citizen scientists possess large amounts of biodiversity data. Potentially, that data could be transferred to the internet using services such as iNaturalist and eBird, unfortunately, these services do not possess the ability for large-scale (bulk) data input (Kelling et al., 2009). Widely known IS, such as the Global Biodiversity Information Facility (GBIF) and iDigBio, are capable of aggregating large amounts of biodiversity information worldwide. However, such services do not allow for direct user input of original records. Specify and Symbiota are software-based projects designed for herbaria and collection curation (Beach, 2019; Gries et al., 2014). These IS are not free, however, they have many users and support community. In contrast, some other projects such as DINA and Jacq are working according to open access philosophy (Macklin et al., 2018, Vissers et al., 2017). eElurikkus is a well-built regional data aggregator/portal (https://elurikkus.ee) dealing with Estonian biodiversity, it uses PlutoF as a data management service (Abarenkov et al., 2010). It is still possible to increase the flow of information in the biological sciences with the help of a modern, open-access IS that allows for bulk input of user-collected data.

The aim of the Cryptogamic Russian Information System (CRIS, http://kpabg.ru/cris) is to provide a tool for herbaria and collections to organize/analyze specific biodiversity data of the cryptogams. It accumulates primary biodiversity information about biological specimens, which are being stored in the herbaria/culture collections, providing free access to the digital records of these specimens. CRIS has been created to fulfill the aims of the cryptogamic botanists, who were not satisfied with other IS. Here, we give the overview of the system and capabilities of CRIS and let readers decide how suitable it is for their particular goals. 
Initially, CRIS was based on Hypertext Preprocessor scripts (PHP) along with DB Management System (DBMS) MySQL, allowing only for one person to enter and manipulate herbarium data at a time. Later, CRIS was migrated to the internet, increasing ease of access for local users. It also provided the opportunity for individuals outside of the Polar-Alpine Botanical GardenInstitute (PABGI) to access CRIS. Because of the change in development strategy, CRIS was successfully transferred to the Content Management System (CMS) Drupal with expanded features such as geo-information environment, and others (Melechin et al., 2013). After that, CRIS utilized more appropriate MariaDB instead of MySQL and was moved to an independent server. CRIS has recently transitioned to using PostgreSQL, with the aim of allowing users to generate searches using polygon-based graphical selection. CRIS is currently being transitioned from out-of-date Drupal to Node. js, which will increase the speed and simplicity of CRIS. The consistent functioning of CRIS for the past 10 years will ensure a productive future for this database.

\section{DATA STRUCTURE OF CRIS}

The main types of records supported by CRIS are observations, herbarium specimens, literature records, and records from other sources. Observation records contain an entry with information about a natural observation of an individual or multiple cryptogam(s) growing together. This type of record is entirely digital and lacks the proof by a physical herbarium specimen. Observation records contain GPS coordinate for the entry and an image of the cryptogam(s). Akin to the records of the web service iNaturalist, observation records in CRIS usually include common species.

Since CRIS catalogues data from several herbaria, every record is appended with an abbreviation for that particular collection. The digital record is connected with a physical specimen via a local herbarium reference (LID) number. Herbarium records include all general information including collection site, geographical data (e.g. GPS coordinates), name of collector and person determined species, etc. More or less detailed description of the microhabitat is typically presented in this type of record. Lastly, a list of the species found in the sample is also included. One to fifteen species may be identified from a single microcolony/mat. In CRIS, all species from an herbarium record are connected to the single geographical location (similar to PlutoF), which is in contrary to GBIF, where, for example, two different species from a single herbarium specimen are connected to the cloned geographic records, each of those attached to the independent IDs. Even though data in CRIS are organized differently from GBIF, it is possible to transform CRIS data into the Darwin Core format. For that, the data could be exported from CRIS into the table, and the fields which are missing in Darwin Core remain blank, the rest are autofilled. To import Darwin Core data into CRIS, CSV table should be exported from appropriate IS, and then it can be included into the CRIS with a reference to the source. Additionally, CRIS has the option which may clone records with similar information. That increases productivity of data input. In fact, it allows entering more than 20 records in an hour.

Literature records are records showing species locality from already published research. These records are displayed on easy-to-read maps. It is quite useful for both biogeographic and taxonomic revisions. Lastly, records from other sources include data from sources outside of the CRIS DB. These can include data from another IS, electronic resources, etc. Besides single record input, there is an option for large-scale (bulk) record input, while information for this must be properly formatted in spreadsheets.

There are several user types in CRIS: common user, registered user, supervisor, and administrator. Common users (unregistered visitors) can access search tools and data filtering, without the ability to enter original data. In contrast, registered users (after registering a free account) can enter and edit original data and print labels for herbarium specimens. The supervisor reviews and corrects errors in taxonomy, searches, checklists and other blocks of data within a single section of CRIS (e.g., a cyanobacterial expert would be given a supervisorial account for the cyanobacteria section of CRIS). Administrators have access to every section and all collections. The function of the administrator is to control system functionality and provide data and web security. The administrator updates CRIS with 
modern tools and features, following the suggestions of registered users and supervisors.

Using the herbarium function, CRIS enables users to monitor and keep track of specimen exchange between herbaria. With the implementation of semi-automatic tools available on CRIS, it is convenient to keep track of specimen movement within or outside of particular herbarium. Additionally, CRIS allows the allocation of responsibilities between curators and registered users in terms of taxonomy monitoring, as well as data entry for individual projects. Utilization of free software such as Linux operating systems, DBMS PostgreSQL, and CMS Drupal provides CRIS with essential functionality, which has been tested and improved upon during its formative years. Moreover, our experience working on cryptogam's biodiversity for the decades lead us not to use any existing data format, including Darwin Core. The main reason is that CRIS requires some specific fields for cryptogams in the data tables, which are just missing in the Darwin Core.

\section{SEARCH OPTIONS IN CRIS}

There are several options available for searching CRIS:

Annotated species list. Search for all species records from a particular geographic region, such as a country or protected areas (e.g., national parks).

Species lists of the area. If a user is searching for a list of the species from a particular territory, including multiple national borders or reserves, such as the High Arctic or Eurasia, the user needs to create a polygon in the appropriate tab using the provided polygon selection tool. The output of that search is the list of all species; by clicking on the particular polygon, a user may see the list of all occurrences of a species inside the polygon. Additionally, this search option will output a map with flags corresponding to each occurrence. By selecting a flag, a user can see information about that record, including target species.

Species list. A user may search by country, location, or substrate to filter through all records. Additional filters are available in the species list search such as filtering by subspecific-level taxa only [e.g., varieties (var.) or subspecies (subsp.)]. The number of taxa is also shown at the top of the list.

Specimen search. A user may search specimens by country, region, locality, or date of collection. The output consists of the list of specimens with a short annotation and collection number. Selecting type of material on the left-hand side will lead to the multispecies record.

Occurrences. This search will show all location points of a species in the form of an annotated list. By clicking on hyperlinks more detailed information about a specimen will be available.

Species distribution. This option searches for a single species, with output in the form of a map with selectable flags that link to the multispecies record. Filtering by region is also available.

Synonyms. A user may find species using nomenclatural synonyms; the output will be in the form of lines with the correct name of the taxon and number (in parentheses) of appropriate records.

Photos. This type of search may be used for accessing graphical images of the species or genera, and their habitat. By selecting the thumbnail preview, a user is redirected to the full-resolution photo and can freely use it with reference to the source and the author. Approximately 3500 original photos of cyanobacteria, lichens, fungi, and bryophytes are presently available.

References. That search provides records from literature sources. Filters by country, region, species, author, and literature title are available.

Sequence files search/GenBank search. The output of that DNA files search is the list of the taxa with .TXT files attached, containing original DNA sequences prior to submission to the GenBank. GenBank number search provides a list of records with accession numbers available.

Taxa above genus rank. This search allows a user to search by higher taxonomic ranks such as families, orders, etc.

\section{CONTENT OF CRIS}

Since 2007, CRIS has grown into a rather large IS and includes five different sections devoted to cyanobacteria, lichens, fungi, liverworts, and mosses with several thousand records, as well as a great number of species and habitat 
images (Davydov et al., 2017). Currently, CRIS is cataloguing more data than described in Melechin et al. (2013) due to information input from PABGI and other Universities/Institutions. At present, several institutions, such as Institute of Industrial Ecology problems in the North (INEP), Samara State University (SMR) and John Carroll University (JCU) are using CRIS as their primary tool for cataloguing biodiversity information. On average, data in CRIS are mostly collected from different Russian territories. Liverworts and mosses make up the majority of records in CRIS with around 44,000 and 25,219 records, respectively. All records from these groups are derived from herbarium material. Cyanobacterial records comprise 1637 herbarium samples, 1480 collections samples, and 87,835 datasets from other sources. The majority of records in CRIS are from the Murmansk region (Fig. 1) and the Svalbard Archipelago (Figs. 2-4). Brief descriptions of data for different cryptogam sections are given below.

CYANOBACTERIA. CYANOpro is the section of the CRIS devoted to cyanobacteria. This section of CRIS contains data from the herbarium of cy- anoprokaryotes KPABG, cyanobacteria culture collections of the PABGI and the JCU Culture Collection (JCUCC, Cleveland), and the culture collection of cyanoprokaryotes and algae of the Institute of Biology of the Komi Science Center of Ural branch of RAS (SykoA, Syktyvkar). CYANOpro includes $>100,000$ records of cyanobacteria from other sources, mostly from Sweden and Norway territories. CYANOpro unites comprehensive dataset of the material collected from the Eurasian Arctic and Hypoarctic (Davydov, Patova, 2018; Fig. 2). Recent collections from the Svalbard Archipelago (750 specimens) and Murmansk Region (800) are also represented in CYANOpro. The utilization of CYANOpro united data from several research projects devoted to cyanobacteria (Davydov, 2016, 2017). Lastly, several new cyanobacterial taxa have been described using CYANOpro as an information tracking tool, from sample collection and strain isolation to DNA analysis (Shalygin et al., 2017, 2018, 2019a, 2019b).

Lichens. The described lichen biota of the Murmansk and Samara Regions are almost entirely represented in the lichen section of CRIS, with

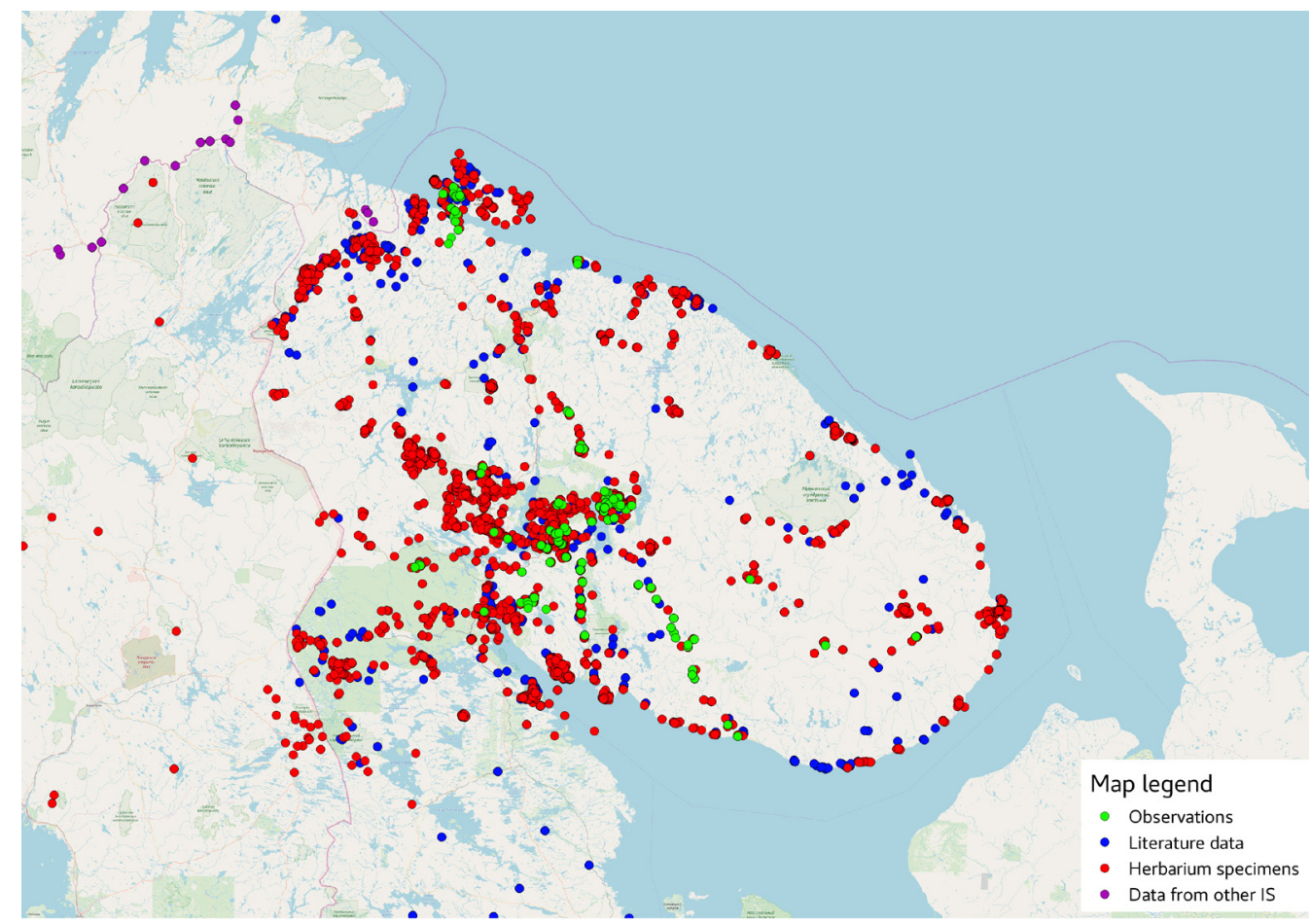

Fig. 1. Records of all cryptogams from Murmansk Region in CRIS. 


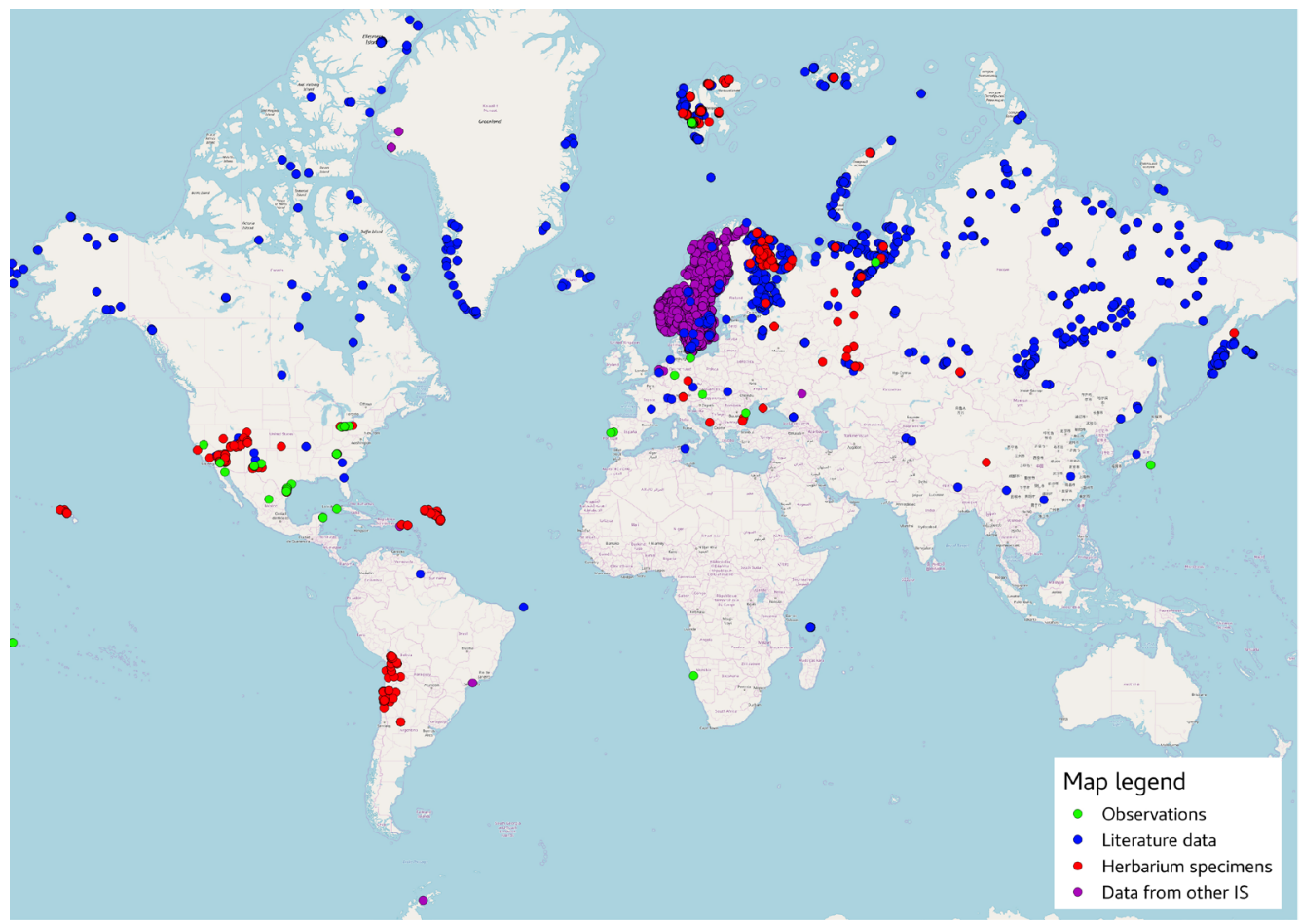

Fig. 2. Records of cyanobacteria in CRIS.

$100 \%$ and $80 \%$ of recorded species, respectively. For most of the species from the Murmansk and Samara Regions, several specimen records have been entered into CRIS, bringing unique biogeographic and ecological insights. Besides the 12,000 herbarium records, 87 literature sources have been incorporated into the lichen section of CRIS (Fig. 3). The "Dynamic checklist of lichens of the Murmansk Region" section of CRIS is currently the most comprehensive and consistently updated list of lichens for the region, currently including 1159 species of lichens. CRIS is also one of the most important sources of information about the lichen biota of Svalbard. Nearly 2000 recently collected specimens ( 40\% of the lichen biota of Svalbard) from different territories of Svalbard are presented in CRIS. Data from other regions are less complete and do not exceed $30 \%$ of the total number of species for the Tula and Belgorod Regions, 20\% for Orenburg and Chelyabinsk Regions, and 10\% for the Perm' Territory and the Republic of Karelia. Currently, CRIS contains records of 833 species of lichens that are accompanied by high-quality images of both habitat and morphology. Lastly, the lichen section of CRIS has been used for distribution analyses of several lichen species (Melechin, 2015, 2016).

BRYOPHYTES. For following analysis, data for liverworts and mosses have been combined under a single "Bryophytes" section for the simplicity. Technically, these sections are separated into individual subsections. The bryophyte section of CRIS incorporates herbarium records from the herbarium of bryophytes of PABGI (KPABG, Apatity), INEP herbarium (Apatity), herbarium of liverworts (partly) of the Botanical GardenInstitute of the Far East branch of the Russian Academy of Sciences (VBGI, Vladivostok), and Kandalaksha State Nature Reserve (KAND, Kandalaksha). It is likely that CRIS is the most complete source of information for liverworts and mosses of the Murmansk Region (7468 and 20,130 specimens, respectively). Data from regions within the aforementioned territory (Fig. 4) includes most of the known distribution records for these taxa. These data are quite complete and provide a quality basis for future work on the bryoflora on the Murmansk Region. Addition- 


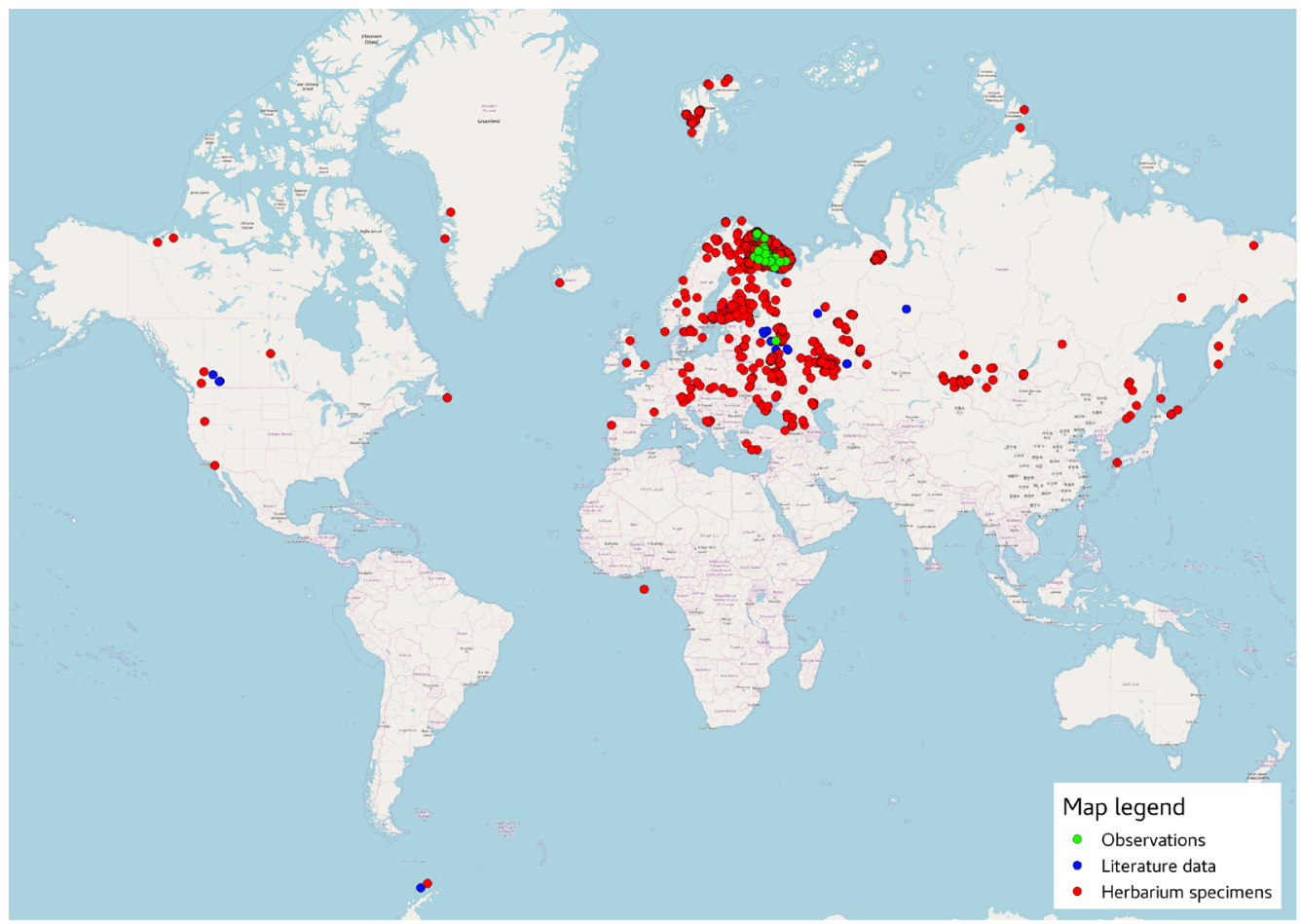

Fig. 3. Records of lichens in CRIS.

ally, CRIS includes data of the recent collections of bryophytes of Svalbard Archipelago (1000 specimens of liverworts and 1050 specimens of mosses) as well as liverworts of the Russian part of Caucasus (1859 records), Urals (2111), South Siberia (1800), the middle part of Russia (600), Far East of Russia (4232), and Russian Arctic (700). Many recent publications on liverwort diversity of different regions of Russia are supported by data in CRIS (Borovichev, 2014; Borovichev \& Boychuk, 2016; Borovichev \& Shorohova, 2019; Konstantinova \& Lapshina, 2017; Mamontov \& Konstantinova, 2017). Importantly, apart from the names of administrative units and countries, the majority of records include coordinates, elevation, and detailed habitat descriptions. Records may also include taxonomic and morphological notes for species, such as the presence of gametangia and perianths or different kinds of propagules. Most recent records are in English, whereas older records are primarily in Russian. Names of regions are given in English for all records, making it possible for English speakers to search distribution data. Literature sources and pictures are rather limited, whereas DNA sequences for bryophytes are present for many studied specimens.

\section{CRIS IN COMPARISON WITH OTHER IS}

CRIS has particular features that make it appealing to use. First, there is no need to utilize specific software to input the primary data. User should have only browser and internet connection for that. CRIS is close to PlutoF in terms of ability to attach as many species to one locality as possible in the body of a single record. However, it differs in the way how data communicate and are shared through global aggregators. PlutoF is basically data managing system connected to the global data portal eElurikkus, where data analysis and photographic materials are available. In contrary, CRIS does not have such demarcation, it is uniting primary and secondary IS. Second, CRIS possesses easy input and transformation of the single records of any available collections, any time through the browser. Third, it has the ability to "clone" single record for the specimens with similar lo- 


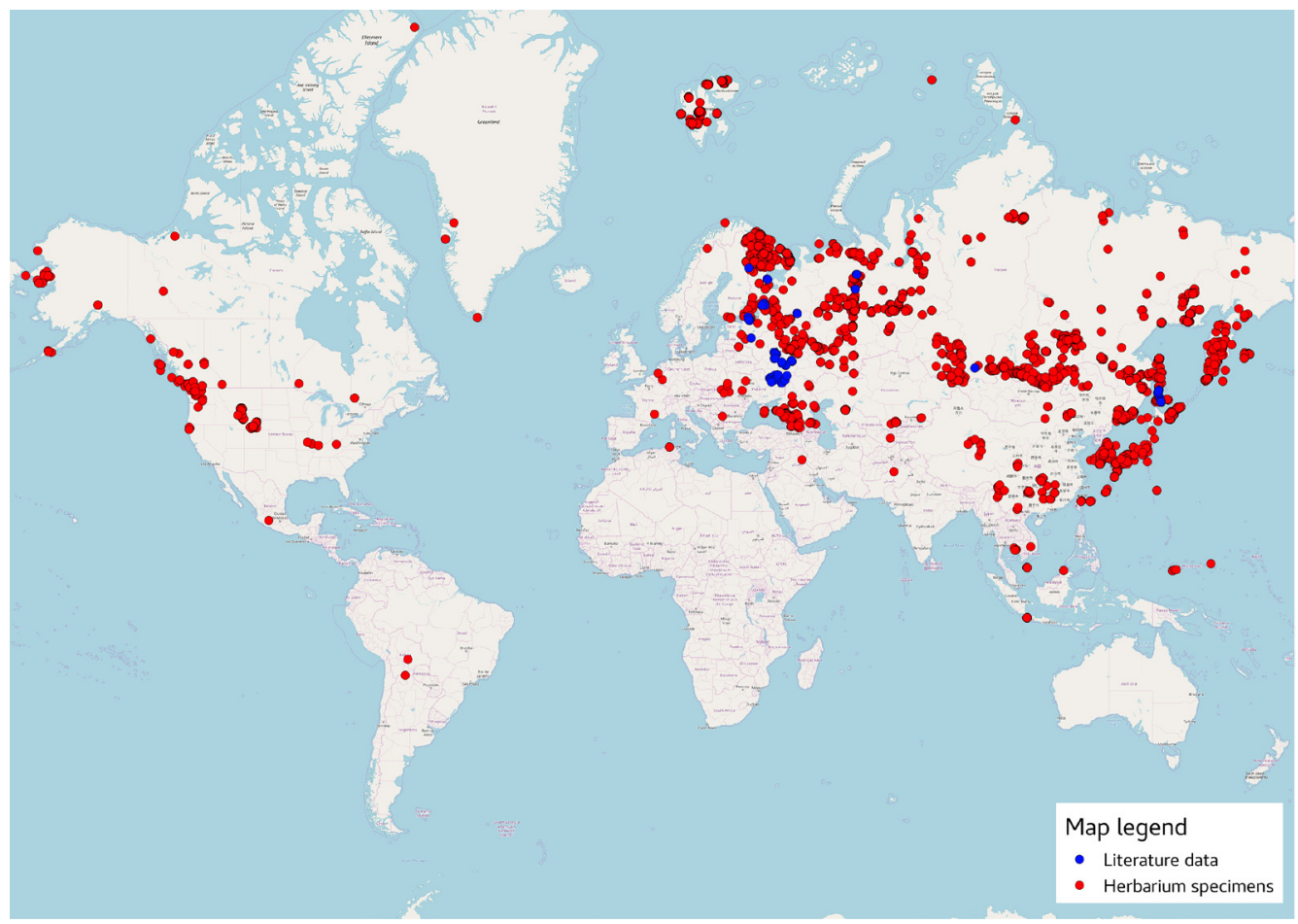

Fig. 4. Records of bryophytes in CRIS.

cation/habitat. Lastly, there is no limitation of the data types allowing to use any data tables and all fields which could serve as the base for the subsequent analysis.

At present, many biodiversity information systems are available on the web. In our comparative analysis, projects based on specific, proprietary software (e.g., Specify and Symbiota) were excluded. CRIS is a combination of both, a primary IS which allows input and transformation of the biodiversity data, such as PlutoF, DINA etc., and secondary IS. These allow to aggregate, storage and analyze data, such as eElurikkus, GBIF and Atlas of Living Australia (Table 1). Some of secondary systems could include both original herbarium records and aggregate data from another IS. Many other IS, such as iNaturalist, EOL are functioning in the similar way. Unlike iNaturalist, iDigBio, and some Russian systems (e.g., Baikal Siberia and Noah's Ark), CRIS includes nearly all possible types of data (Table 1). Like the majority of IS in our analysis, CRIS is capable for the input of massive datasets. In contrast to GBIF and iDigBio, it is possible to edit individual records in CRIS. CRIS is a data aggregating system possessing some statistical inference functions, which is similar to NYBG, iDigBio, and others. Importantly, CRIS can generate and print herbarium labels which is a rare function in global IS (Table 1). Along with most of the other IS, CRIS provides images of species, however, CRIS is a unique system in that it also provides habitat images as well. KE Emu based IS (e.g., NYBG) are quite convenient and widely used in North American herbaria, unfortunately, these programs are not free and can be quite costly.

\section{PERSPECTIVES AND FUTURE DIRECTIONS OF CRIS}

Because of the rapid increase of records, frequent user requests, as well as an increase in the number of groups cataloguing organisms, we have made the decision to switch from CMS Drupal to Node.js. This transition is still in progress and will hopefully be complete soon. It will increase the functionality in the manipulation of data entry forms that can be configured for each 


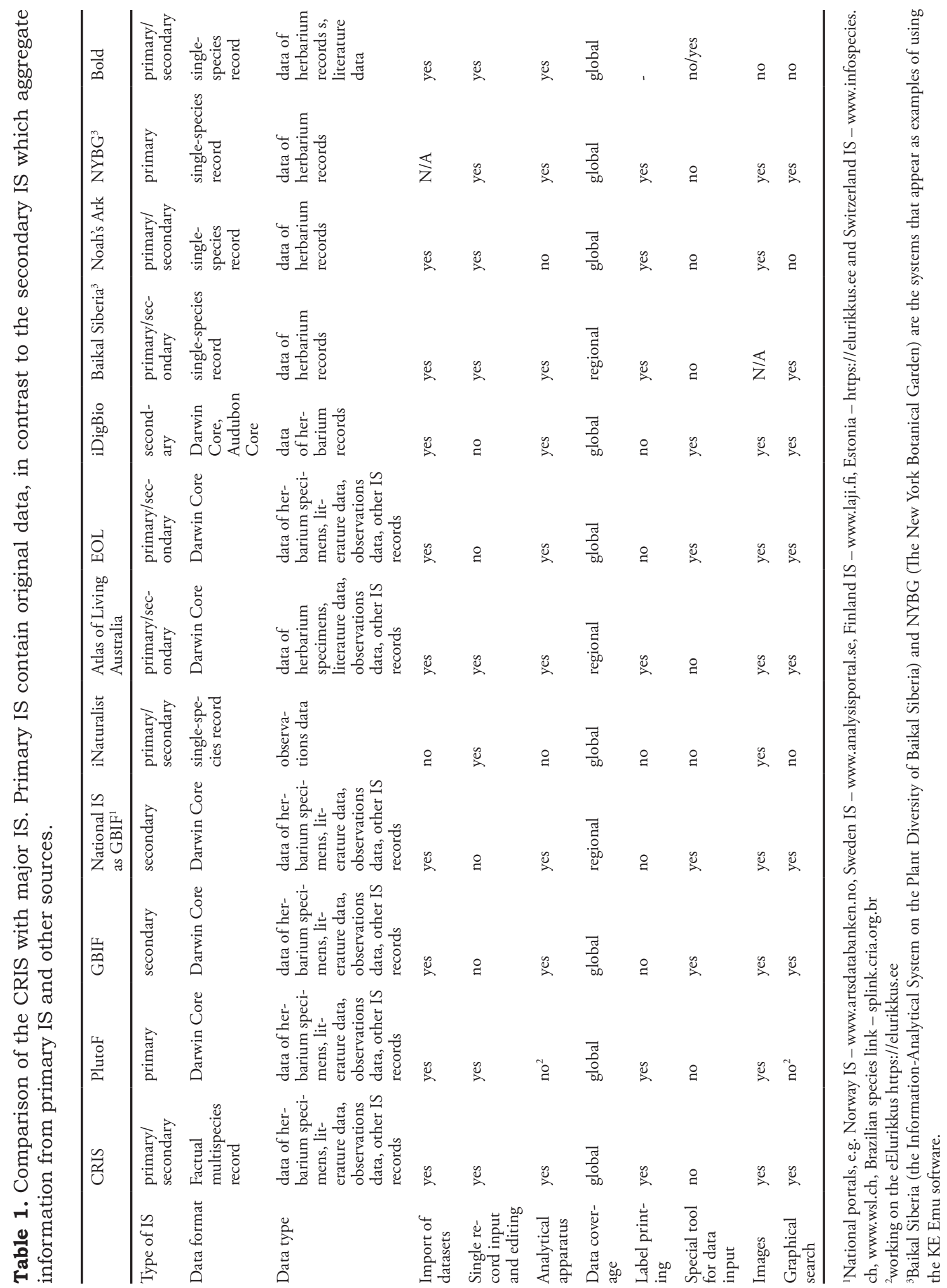


user's tasks: add custom fields, hide optional fields of other users, and other customizations. We hope that the new IS version will be free from the defects of the current CRIS platform and will solve the problem of server resource overloads. The new version of CRIS will have an intersectional search ability, this functionality will be accomplished by connecting the different cryptogram sections of CRIS.

While we were working on CRIS during the past years, we were faced with the problem of data integration from technical specialists, herbarium curators, and botanists. One of the reasons why some local IS choose not to become a section of CRIS is that differences in data format has prevented them from successfully integrating their data. Another potential problem related to integration is that curators using a particular IS for many years often lack motivation to use a new data organization method. Because of that we have increased the flexibility of our IS for the needs of different users by including as many blank fields as needed for a single record. A newly developed tool, which can show/hide any data on the internet, is another way we hope to attract local IS to join CRIS. If user does not want unpublished records to be accessible by the public, it is possible to hide them until they are ready to be published. In this case, hidden records are visible only registered users or curators. With that new function, we expect an increased likelihood for representatives of other local IS to join CRIS. Another reason hindering the integration of local IS into CRIS is differing views on taxonomy. If a collection or herbarium is making its own IS and are not willing to use CRIS as the primary platform for storing biodiversity data, it is possible to import spreadsheet with information from that collection into CRIS via the mass import function. CRIS provides quality, free access to biodiversity data as well as the opportunity to enter original data. Release of the new version of the CRIS is planned for January, 2020.

\section{ACKNOWLEDGEMENTS}

We acknowledge Cory Gargas (University of Arkansas, USA) for making constructive writing suggestions, which improved this manuscript substantially. We are also grateful to two reviewers and chief editor for carefully reading the manuscript and valuable comments. The study was carried out within institutional research project of the Avrorin Polar-Alpine Botanical Garden-Institute, RAS, No 0229-2016-0004 and partial support of grants from Russian Foundation for Basic Research (projects No 1529-02662, 18-04-00171, 18-04-00643).

\section{REFERENCES}

Abarenkov, K., Tedersoo, L., Nilsson, R. H., Vellak, K., Saar, I., Veldre, V., Parmasto, E., Prous, M., Aan, A., Ots, M., Kurina, O., Ostonen, I., Jõgeva, J., Halapuu, S., Põldmaa, K., Toots, M., Truu, J., Larsson, K.-H., Kõljalg, U. 2010. PlutoF-a Web Based Workbench for Ecological and Taxonomic Research, with an Online Implementation for Fungal ITS Sequences. Evolutionary Bioinformatics 6: 189-196. https: / / doi.org/10.4137/EBO.S6271

Altman, R. B. 2004. Editorial: Building successful biological databases. Briefings in Bioinformatics 5(1): 4-5. https://doi.org/10.1093/bib/5.1.4

Beach, J. 2007. Specify Biodiversity Collections Software. http:/ /www.specifysoftware.org/Specify/. (access May, 2019).

Bisby, F. A. 2000. The Quiet Revolution: Biodiversity Informatics and the Internet. Science 289(5488): 2309-2312. https://doi.org/10.1126/science.289.5488.2309

Borovichev, E. A. \& Boychuk, M. A. 2016. Checklist of liverworts of the Pasvik State Nature Reserve (Murmansk region, Russia). Folia Cryptogamica Estonica 53: 1-8. https://doi.org/10.12697/ fce.2016.53.01

Borovichev, E. A. 2014. Checklist of liverworts of the Lapland State Nature Biosphere Reserve (Murmansk Region, Russia). Folia Cryptogamica Estonica 51: 1-11. https://doi.org/10.12697/ fce.2014.51.01

Borovichev, E. A. \& Shorohova E. V. 2019. The liverwort flora of Karelian part of the Vodlozersky National Park (Russia). Folia Cryptogamica Estonica 56: 77-85. https://doi.org/10.12697/ fce.2019.56.08

Bourne, P. 2005. Will a Biological Database Be Different from a Biological Journal? PLoS Computational Biology 1(3), e34. https://doi.org/10.1371/journal.pcbi.0010034

Davydov, D. \& Patova, E. 2018. The diversity of Cyanoprokaryota from freshwater and terrestrial habitats in the Eurasian Arctic and Hypoarctic. Hydrobiologia 811(1): 119-138. https://doi. org/10.1007/s10750-017-3400-3

Davydov, D. 2016. Cyanoprokaryota of the Polisarka, Pana, Varzuga Rivers District (Murmansk region, Russia). International Journal on Algae 18 (4): 387-395. https://doi.org/10.1615/InterJAlgae. v18.i4.80 
Davydov, D. 2017. Cyanoprokaryotes of the west part of Oscar II Land, West Spitsbergen Island, Spitsbergen archipelago. Czech Polar Reports 7(1): 94-108. https://doi.org/10.5817/CPR2017-1-10

Davydov, D. A., Melekhin, A. V., Konstantinova, N. A. \& Borovichev, E. A. 2017. Possibilities of Cryptogamic Russian Information System. In: Borovichev, E.A, Davydov, D.A. \& Koroleva, N.E. (eds). International Conference "The use of modern information technologies in botanical investigations", K\&M, Apatity: 32-34. (In Russian)

Gries, C., Gilbert, E., \& Franz, N. 2014. Symbiota - A virtual platform for creating voucher-based biodiversity information communities. Biodiversity Data Journal 2, e1114. https:/ / doi.org/10.3897/ BDJ.2.e1114

Ivanova, N. V. \& Shashkov, M. P. 2017. Biodiversity Databases in Russia: Towards a National Portal. Arctic Science 3(3): 560-576. https://doi. org/10.1139/AS-2016-0050

Kelling, S., Fink, D., Wood, C. L., Iliff, M. J., Sullivan, B. L. \& Bonney, R. E. 2009. eBird: A citizen-based bird observation network in the biological sciences. Biological Conservation 142(10): 2282-2292. https://doi.org/10.1016/j.biocon.2009.05.006

Konstantinova, N. A. \& Lapshina, E. D. 2017. The hepatics of the Upper Puiva River (Sub-Polar Ural, Khanty-Mansy Autonomous District). Arctoa 26: 35-46. https://doi.org/10.15298/arctoa.26.03

Macklin, J., Englund, M., Glöckler, F., Heikkinen, M., Hoffmann, J., Newton, K. \& Ronquist, F. (2018). General introduction to DINA. Biodiversity Information Science and Standards 2, e25646. https: / / doi.org/ 10.3897/biss.2.25646

Mamontov, Yu. S. \& Konstantinova N. A. 2017. Liverworts of Irkutsk Region. Botanicheskiy Zhurnal [Russian Botanical Journal] 102(4): 494-519. (In Russian)

Melechin, A. V. 2015. Records of new and rare lichens for Svalbard. Graphis Scripta 27(1-2): 56-58.

Melechin, A. V. 2016. Gyalecta biformis and Gyalidea diaphana new to Russia. Graphis Scripta 28(1-2): 11-13.

Melechin, A. V., Davydov, D. A., Shalygin, S. S. \& Borovichev, E. A. 2013. Open information system on biodiversity cyanoprokaryotes and lichens CRIS (Cryptogamic Russian Information
System). Bulleten MOIP. Department of Biology [Bulleten MOIP. Otdel biologicheskiy] 118: 51-56. (In Russian).

Shalygin, S., Huang, I., Allen, E. H., Burkholder, J. M. \& Zimba, P. V. 2019a. Odorella benthonica gen. \& sp. nov. (Pleurocapsales, Cyanobacteria): an odor and prolific toxin producer isolated from a California aqueduct. Journal of Phycology 55: 509-52. https://doi.org/10.1111/jpy.12834

Shalygin, S., Kavulic, K. J., Pietrasiak, N., Bohunická, M., Vaccarino, M. A., Chesarino, N. M. \& Johansen, J. R. 2019b. Neotypification of Pleurocapsa fuliginosa and epitypification of $P$. minor (Pleurocapsales): resolving a polyphyletic cyanobacterial genus. Phytotaxa 392(4): 245. https:// doi.org/10.11646/phytotaxa.392.4.1

Shalygin, S., Pietrasiak, N., Gomez, F., Mlewski, C., Gerard, E. \& Johansen, J. R. 2018. Rivularia halophila sp. nov. (Nostocales, Cyanobacteria): the first species of Rivularia described with the modern polyphasic approach. European Journal of Phycology 53(4): 537-548. https://doi.org/ 10 .1080/09670262.2018.1479887

Shalygin, S., Shalygina, R., Johansen, J. R., Pietrasiak, N., Berrendero Gómez, E., Bohunická, M., Mareš J. \& Sheil, C. A. 2017. Cyanomargarita gen. nov. (Nostocales, Cyanobacteria): convergent evolution resulting in a cryptic genus. Journal of Phycology 53(4): 762-777. https:/ / doi. org/10.1111/jpy. 12542

Shanmughavel, P. 2007. An overview on biodiversity information in databases. Bioinformation 1(9): 367369. https: / / doi.org/10.6026/97320630001367

Veiga, A. K., Saraiva, A. M., Chapman, A. D., Morris, P. J., Gendreau, C., Schigel, D. \& Robertson, T. J. 2017. A conceptual framework for quality assessment and management of biodiversity data. PLOS ONE 12(6), e0178731. https://doi.org/10.1371/ journal.pone.0178731

Vissers, J., den Bosch, F., Bogaerts, A., Cocquyt, C., Degreef, J., Diagre, D., de Haan, M., Smedt, S., Engledow, H., Ertz, D., Fabri, R., Godefroid, S., Hanquart, N., Mergen, P., Ronse, A., Sosef, M., Stévart, T., Stoffelen, P., Vanderhoeven, S. \& Groom, Q. 2017. Scientific user requirements for a herbarium data portal. PhytoKeys 78: 37-57. https:/ / doi.org/ 10.3897/ phytokeys.78.10936 